\title{
Clinical and scintigraphic comparison of silicone and polyvinylpyrrolidone coated silicone perforated plugs
}

\author{
Th Malet, B Challier, N David, A Bertrand, J-L George
}

\begin{abstract}
Backgroundlaim-Isolated stenosis of the lacrimal punctum is a frequent cause of epiphora. Treatment relies on surgical opening or dilatation with bi- or monocanalicular prosthesis. Recently, silicone perforated punctum plugs (PPP) were proposed. The drawback with these silicone PPP was that secretions accumulate in the central orifice blocking the spontaneous flow of tears. A modification of the surface of the PPP using polyvinylpyrrolidone (PVP) was thus proposed. The aim was to compare silicone PPP with new PVP surface treated PPP.

Methods-A prospective study was conducted of 20 patients with dilatable stenosis of the lacrimal puncta who developed epiphora. Epiphora, tolerance, implantation of the PPP, and lacrimal drainage were evaluated using scintigraphy of the lacrimal ducts.

Results-The raw data and statistical analysis showed evidence of a superior performance of PVP surface treated PPP. Conclusion-Long term evaluation of the advantages or risks of PVP plugs and comparison with microsurgical punctoplasty are warranted.

(Br f Ophthalmol 1998;82:1416-1419)
\end{abstract}

Service

d'Ophtalmologie, Centre Hospitalier

Universitaire de

Nancy, Nancy, France

Th Malet

J-L George

Service

d'Informatique, Centre Hospitalier

Universitaire de

Nancy, Nancy, France

B Challier

Service de Médecine

Nucléaire, Centre

Hospitalier

Universitaire de

Nancy, France

N David

A Bertrand

Correspondence to:

J-L George, Service

d'ophtalmologie, Centre

Hospitalier Universitaire de

Nancy, Rue de Morvan,

54511 Vandoeuvre Cedex,

France.

Accepted for publication 18 June 1998

Isolated stenosis of the lacrimal punctum is a frequent cause of epiphora. The various methods used to augment punctal size include repeated dilatations (generally considered to be ineffective), surgical opening by the one snip, two snip, three snip, or punch punctoplasty; microsurgical punctoplasty with sutures; electrocautery; laser treatment; or temporary punctal stenting (canalicular tubing, punctum plugs). Surgical opening by punctoplasty usually gives excellent functional results with few complications. ${ }^{1-3}$ However, an advantage of temporary stenting is to spare the punctal fibrous ring.

Recently, perforated punctum plugs (PPP), proposed by Bernard and colleagues in France, ${ }^{3 a}$ were developed from the punctum

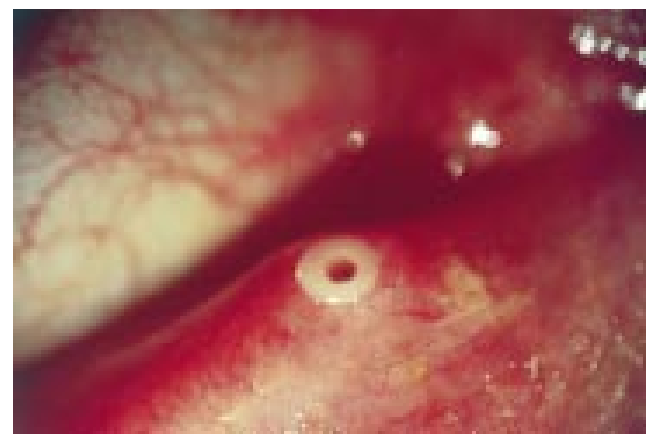

Figure 1 Perforated plug at day 60 with good tolerance.

plugs used for dry eye syndrome. Like ordinary punctum plugs, perforated plugs are made of silicone but are slightly larger and are perforated in the centre. The central orifice measures $0.6 \mathrm{~mm}$ in diameter. However, the first trials were disappointing as these perforated plugs became filled with secretions which accumulated in the central orifice thus blocking spontaneous tear flow. The hydrophilic nature of silicone is thought to be the causal factor. New perforated plugs surface treated with hydrophilic polyvinylpyrrolidone (PVP) were thus developed (FCI Laboratories, 20, boulevard Gallieni BP 111, 92134 Issy Les Moulineaux Cedex, France) (Fig 1).

The aim of this study was to compare two

types of perforated plugs on the basis of drainage efficacy and functional tolerance. To obtain an objective evaluation of lacrimal drainage under good physiological conditions, we used lacrimal scintigraphy. Our purpose was to conduct a clinical trial and was not, at this stage, to compare this new concept with previous punctoplasty procedures.

\section{Materials and methods (Table 1)}

This prospective study was carried out using a single blinded method (patients). Twenty patients gave their informed consent. All 20 patients had epiphora caused exclusively by bilateral dilatable stenosis of the inferior lacrimal puncta. All had patent lacrimal ducts.

Table 1 Study protocol for silicone versus PVP perforated punctum plugs (PPP)

\begin{tabular}{llll}
\hline Selection D-30 to D-8 & Inclusion D1 & D60 & D180 \\
\hline$\bullet$ punctum size & $\bullet$ punctum size & $\bullet$ plug lumen, secretions & $\bullet$ punctum size or plug lumen \\
$\bullet$ prior washing & $\bullet$ epiphora score & $\bullet$ tolerance & $\bullet$ epiphora score \\
& $\bullet$ lacrimal scintigraphy & $\bullet$ epiphora score & $\bullet$ washing \\
& $\bullet$ PPP implantation & $\bullet$ lacrimal scintigraphy & \\
& & $\bullet$ removal of PPP according tolerance & \\
\hline
\end{tabular}

*Perforated plugs were removed in case of mediocre tolerance: $20 / 20$ for silicone, 10/20 for PVP. 
SELECTION

Prestudy

Patients were selected at an initial consultation, if dilating the inferior lacrimal puncta facilitated permeability and canaliculi washing. To be selected, patients had to consider that their epiphora had improved for at least 1-2 days after dilatation. The patients selected were asked to return for an inclusion consultation 8 days to 1 month later.

\section{INCLUSION CONSULTATION}

Implantation (day 1)

At this consultation, the patient's epiphora was scored on a scale from 0 to $3(0=$ no epiphora; 3 = permanent epiphora). Scintigraphy of the lacrimal ducts was performed to obtain an objective measurement of physiological tear drainage. The flow of radioactive dye from the interpalpebral fissure into the lacrimal sac was observed. An area of interest encompassing the interpalpebral fissure and canaliculi was outlined on the display terminal. Scintigraphy results were scored by the same operator on a scale from 1 to 4 ( $1=$ normal drainage; $4=$ no drainage).

A two step method was chosen to render the hydrophobic surface hydrophilic (Docteur Legeay, Centre de Transfert de Technologie du Mans, 20 rue Thales de Milet, Technopole Univers, 72000 Le Mans, France). Firstly, the silicone surface was activated with a cold plasma method. The treatment created radial reactive sites where a molecule or a deposit can attach. In the second step, the object was emerged in a bath of aqueous solution of $18 \%$ polyvinylpyrrolidone (PVP), to deposit a thin layer (1000-2000 $\mathrm{nm}$ ) of the hydrophilic polymer with known biotolerance. This new property is permanent and does not disappear with time either during storage or in vivo. The difficulty in the implantation procedure for the two types of plugs was noted.

The side of implantation was not randomised as the main assessment factor for tear flow after implantation was objective scintigraphy.

Comparative consultation day 60

The patients were seen again 2 months later and epiphora was again scored from 0 to 3 . Tolerance to the PPP was considered to be

- good if there were no secretions collected in the central orifice of the plug and no local irritation (Fig 1)

- mild if pruritus was noted or if secretions were found in the orifice of the PPP

- poor if the accumulation of secretions was sufficient to produce epiphora or if local irritation required removal of the PPP.

A second scintigraphy of the lacrimal ducts was performed with the PPP in position, allowing an objective measurement of tear drainage through the silicone or PVP plugs. Results were scored on the same scale as at the first consultation.

Consultation on day 180

All patients were seen again 6 months later (D180) to assess epiphora and tolerance in
Table 2 Comparative results at day 60 for 20 patients with silicone PPP on one side and PVP PPP on the other side

\begin{tabular}{lll}
\hline & $\begin{array}{l}\text { Silicone PPP } \\
(n=20)\end{array}$ & $\begin{array}{l}P V P P P P \\
(n=20)\end{array}$ \\
\hline $\begin{array}{l}\text { Subjective improvement of epiphora } \\
\text { Tolerance }\end{array}$ & 13 & 15 \\
$\quad$ good & 0 & 15 \\
$\quad$ mild & 15 & 5 \\
poor & 5 & 0 \\
Scintigraphic patency & & \\
$\quad$ improved & 9 & 15 \\
$\quad$ unchanged & 6 & 5 \\
worsened & 5 & 0 \\
\hline
\end{tabular}

those with punctum plugs; or to measure the size of the lacrimal puncta and possible recurrence of epiphora in those in whom the plugs had been removed.

DATA ANALYSIS

Data obtained on day 0 (without punctum plug) for each eye were compared with those for the same eye on day 60 (with punctum plug).The epiphora and scintigraphy scores obtained in the two groups (PVP and silicone PPP) were compared using Wilcoxon's paired test. The distributions of the scores, as well as the small sample sizes, entailed the use of a non-parametric test. The $\alpha$ level for significance was 0.05 .

\section{Results}

The overall results given in Table 2 were submitted to statistical analysis.

\section{EFFECT ON EPIPHORA}

The epiphora score improved in most cases (13 of the 20 patients with silicone plugs and 15 of the 20 with PVP plugs) (Table 2).

However, we were able to compare the two types of PPP only in patients whose initial epiphora score was the same on both sides (Fig 2). Thus, data from 15 patients (patients 2-4, $6-10,13,15-20)$ were retained for statistical analysis. We noted that in five cases, PVP was more effective than silicone.

Taking the epiphora score as a continuous quantitative variable, analysis of variation (initial score minus final score) between PVP plugs and silicone plugs showed that the average improvement in the epiphora score (initial score minus final score) was significantly better $(\mathrm{p}=0.03)$ for PVP plugs (1.35) than for silicone plugs (1.05).

\section{IMPLANTATION OF THE PERFORATED PUNCTUM} PLUGS

Implantation of the PVP plugs was more difficult than for the silicone plugs in the first two patients. PVP being a more elastic material, the technical procedure had to be learnt. Excepting these two cases, there was no significant difference between the two types of plugs.

TOLERANCE (FIG 1)

For the silicone plugs, tolerance was acceptable in 15 cases: patients generally had secretions in the plug orifice. Tolerance was poor in the other five cases; with an intolerance of the col- 


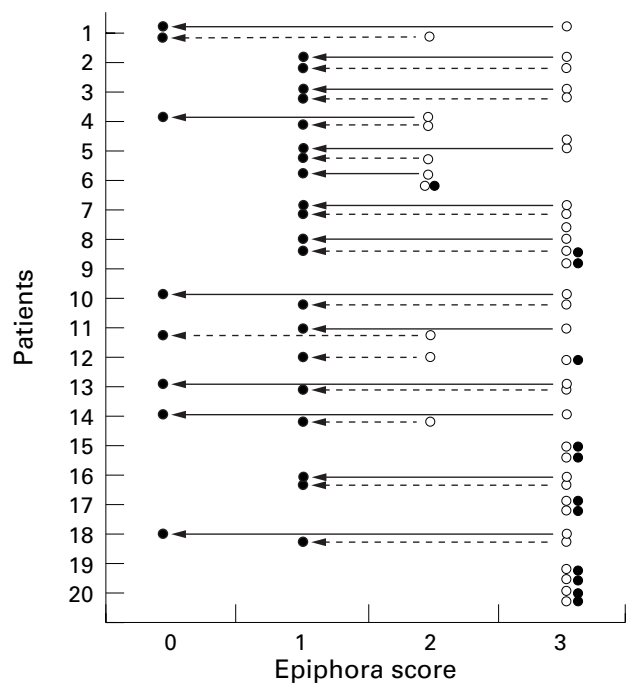

Figure 2 Results for epiphora at day $60(\bullet)$ compared with day 0 ( 0 for perforated plugs (PVP (solid line) versus silicone (broken line)). Epiphora score: 3, permanent; 2 , moderate; 1, mild (wind, coldness); 0, no epiphora.

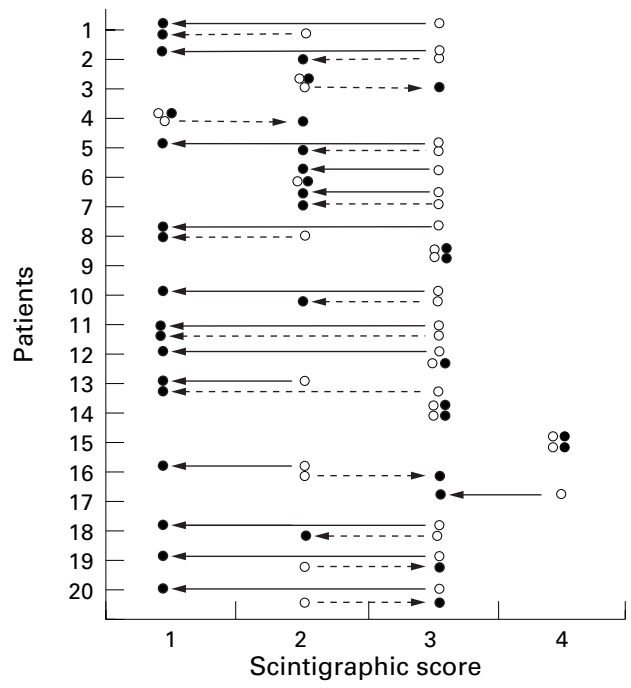

Figure 3 Scintigraphic results at day $60(\bullet)$ compared with day 0 ( $\circ$ for perforated plugs (PVP (solid line) versus silicone (broken line)). Scintigraphic score: 4, no drainage, 3 , reduced with epiphora; 2 , reduced but without epiphora, 1, normal drainage.

lar in one, and excessive accumulation blocking tear flow and requiring removal of the plug in the others.

With the PVP plugs, tolerance was good in 15 cases and mild in five. For these cases, pruritus at the internal angle was the main finding but no secretions were observed in the plug orifice.

SCINTIGRAPHY (TABLE 2, FIG 3)

Scintigraphy results showed an improvement over the initial score for the silicone plug in nine cases, an unchanged score in six, and a worsened score in five.

For the PVP plugs, the initial score was improved in 15 cases and remained unchanged in five. There were no cases with a worse score.

Analysis of the variations in scintigraphy scores (initial minus final) taken as a continuous quantitative variable showed that the difference in the scintigraphy score was signifi- cantly greater $(\mathrm{p}=0.004)$ for PVP plugs $(1.21)$ than for silicone plugs $(0.16)$.

STATISTICAL ANALYSIS

The statistical analysis of these results must be done prudently, as transposing an evaluation of significant difference to one of cause and effect requires random distribution in both groups (PVP and silicone) for all factors which could affect epiphora and scintigraphy. In this trial, each subject was his own control, but the side was not randomised. The two types of plugs were implanted systematically on the same side. Thus, assuming that side had no effect on disease progression, it can be concluded (with reservation) that PVP was superior to silicone.

LATE RESULTS

In the second month, we removed most of the plugs (all the silicone plugs and 10 of the 20 PVP plugs). All patients were seen again at 6 months: a new stenosis of the lacrimal punctum had developed where the plugs had been removed. After initial improvement, epiphora again developed. Surgical opening was required at this point.

The 10 patients with a PVP plug at 6 months did not have epiphora and tolerance was excellent, in particular no secretions were observed in the orifice.

\section{Discussion}

Epiphora with lacrimal flow is caused by many, often intricate, factors. Stenosis of the lacrimal puncta is one of the most frequent causes, suggested by the narrow biomicroscopic aspect of the puncta and the difficulty in dilating the puncta followed by good lacrimal flow in the canaliculi after dilatation. One good clinical argument for punctum stenosis, is transient improvement in tear flow several days after dilatation, before the punctum narrows again. Other arguments for poor tear drainage include a negative taste test, a negative secondary dye test $^{4}$ and, most importantly, the dacryoscintigram which allows good assessment of the physiological situation. ${ }^{5}$

Among the methods proposed for stenosis of the lacrimal puncta, microsurgical opening of the posterior wall of the punctum is the treatment of choice.$^{1-3}$ Despite the high success rate, microsurgery sections the fibrous ring of the punctum, with the subsequent increased risk of stricturotomy if bicanalicular intubation is later required.

Perforated punctum plugs (PPP) were proposed by Bernard et al ${ }^{\text {Ba }}$ with the objective of obtaining a true artificial lacrimal punctum. The advantage over surgery is that the lacrimal sphincter is not ruptured. The qualities of the first PPP, developed from punctum plugs made out of silicone, were their flexibility, elasticity, and antiadherence properties. ${ }^{236-8}$ Unfortunately, this latter property means that the material is hydrophobic, and consequently has a weak surface energy. ${ }^{9}$ It cannot be moistened $^{10}$ and does not favour regular flow of an aqueous fluid. These perforated silicone plugs therefore rapidly became non-functional due to secretions obstructing the central 
orifice. Thus, punctum plugs, whether perforated or not, could be implanted for several weeks, mainly because of their dilating effect. For these reasons, the FCI laboratories along with the Le Mans Centre for Technology Transfer (Dr Legeay) modified the hydrophobic nature of the plugs, making their surface hydrophilic.

Our objective was to evaluate this new prosthesis in comparison with silicone PPP. Our study was performed prospectively by the same operator in a single blind manner before and after implantation of the two types of plugs. To minimise individual factors, the essential inclusion criteria were bilateral stenosis of the lacrimal puncta; latent lacrimal ducts; integrity (verified by prior washing); and transient improvement in tear flow, several days after dilatations.

To minimise individual factors, each patient served as his/her own control, with comparisons between tear flow before and after implantation of the silicone or PVP plug. This eliminated the role of the downstream lacrimal canal whose function is difficult to assess. The role of the superior punctum and canaliculi were also eliminated. ${ }^{11}$

Our results confirmed an improvement in functional signs, both with the silicone and the PVP plugs, for nearly three quarters of patients. Inversely, the objective results (tolerance, secretions in the central orifice of the perforated plugs) showed that the perforated plug with a PVP surface was superior. Scintigraphy of the lacrimal ducts is a recognised method for assessing spontaneous tear drainage in physiological conditions. ${ }^{12}{ }^{13}$ As the scintigraphy curves are objective data, the two types of plugs were not implanted according to a random distribution.

Our scintigraphy recordings before and after implantation of the perforated plugs, confirmed the superior lacrimal drainage with PVP surface treated perforated plugs. There were no cases with poorer isotopic tear flow with the PVP plugs, while we did find evidence of aggravation for five cases with silicone plugs.

Re-stenosis of the lacrimal punctum, observed after ablation of the PPP, raises a problem concerning the concept of lacrimal prostheses: these prostheses should be maintained permanently. Complications can arise with PPP (punctum may tear during the insertion, pyogenic granuloma, expulsion, migration, local irritation). ${ }^{14-18}$ Canalicular stenosis has been described ${ }^{1419}$ with punctum plugs and may be observed with perforated plugs. In our study, treating the surface with PVP improved tolerance, lumen vacuity, and efficacy of lacrimal drainage compared with the earlier silicone perforated plugs. We feel that the PVP plugs could be used as permanent prostheses. Further follow up of patients with these implants is obviously necessary to verify long term tolerance, notably concerning proximal canalicular stenosis.

\section{Conclusion}

Renewed interest in the treatment of lacrimal punctum results from the development of perforated plugs with a PVP surface. Efficacy and tolerance are improved during the first months. If the risk of stenosis after ablation is confirmed, these plugs should be maintained permanently, warranting long term evaluation of the advantages or risks of PVP plugs.

The authors have no proprietary interests in the company or institution mentioned in this paper.

1 Jeancolas D, George J-L, Lesure $\mathrm{P}$, et al. Le traitement microchirurgical des points lacrymaux étroits. Bull Soc Ophtalmol Fr 1987;87:159-61.

2 Offutt W-N, Cowen DE. Stenotic puncta: microsurgical punctoplasty. Ophthalmic Plast Reconstr Surg 1993;3:201-5.

punctoplasty. Ophthalmic Plast Reconstr Surg 1993;3:201-5.
Edelstein J, Reiss G. The wedge punctoplasty for treatment of punctal stenosis. Ophthalmic Surg 1992;12:818-21.

3a Bernard JA, Fayet B, Pouliquen Y. Nouveaux modèles de clous méatiques et de pose-clous. Bull Soc Ophtalmol Fr 1989;89:1131-2.

4 Becker B-B. Secondary dye testing of the lacrimal system. Ophthalmic Surg 1993;242:91-3.

5 Hurwitz JJ, Kirsch J. Nuclear lacrymal scanning in the lacrimal system. Philadelphia: Lippincott-Raven, 1996:73-81.

6 Mateo NB, Ratner BD. Relating the surface properties of intraocular lens materials to endothelial cell adhesion damage. Invest Ophthalmol Vis Sci 1989;30:853-60.

7 Vandervalk P, Vanpelt AW, Busscher HJ. Interaction of fibroblats and polymer surfaces: relationship between free energy and fibroblast spreading. $\mathcal{F}$ Biomed Mater Res 1983; 17:807-17.

8 Yasuda H, Yamanashi BS, Devito DP. The rate of adhesion of melanoma cells into nonionic polymer surfaces. $\mathcal{F}$ Biomed Mater Res 1978;12:701-6.

9 Herzog WR, Peiffer RL. Compairison of the effect of polymethylmethacrylate and silicone intraocular lenses on rabbit corneal endothelium in vitro. 7 Cataract Refract Surg 1987;13:397-400.

10 Chasset R, Legeay G, Touraine JC, et al. Fluoration du polyethylene par plasma froid: mouillabilité, indice limite d'oxygène, coefficient de frottement. Eur Polym $\mathcal{F}$ 1988;24: 1049-55.

11 Reed S, Lissner G. Clinical study on the effectiveness of tear drainage with a single canalicular system under environmental stress. Ophthalmic Plast Reconstr Surg 1993;9:27-31.

12 Hurwitz JJ, Maisey MN, Welham RAN. Quantitative lacrimal scintigraphy. I: Method and physiological application. Br f Ophthalmol 1975;59:308-12.

13 Hurwitz JJ, Maisey MN, Welham RAN. Quantitative lacrimal scintigraphy. II: Lacrimal pathology. $\mathrm{Br} \mathcal{F}$ Ophthalmol 1975;59:313-22.

14 Fayet B, Bennabderrazik S, Bernard JA, et al. Sténose canaliculaire compliquant la pose de bouchon lacrymal: incidence et mécanisme. F Fr Ophtalmol 1992;15:25-33.

15 Fayet B, Bernard JA, Louka B, et al. Complications des bouchons lacrymaux employés dans le traitement des séchersses oculaires. F Fr Ophtalmol 1990;13:135-42.

16 Levenson JE, Hofbauer J. Problems with punctal plugs. Arch Ophthalmol 1989;107:493-4.

17 Maguire LJ, Bartley GB. Complications associated with the new smaller size Freeman punctal plug. Arch Ophthalmol 1989;107:961-2.

18 Nelson C. Complications of Freeman plug. Arch Ophthalmol 1991;101:923-4.

19 Fayet B, Bernard JA, Deligne L, et al. Etude dacryographique de l'étendue des sténoses canaliculaires compliquant la pose de bouchon lacrymal $7 \mathrm{Fr}$ Ophtalmol 1991;10:897-902. 